\title{
Who's keeping count? The need for regulation is a relative matter
}

\author{
Neroli Sawyer, B.Sc. (Hons). \\ School of Behavioural and Social Sciences and Humanities, University of Ballarat, Mount Helen, Ballarat, Victoria, Australia \\ It is important to have an accurate model for calculating limits to sperm donation so as to avoid inadvertent half- \\ sibling mating and help protect the rights and welfare of the donor- inseminated child. The most highly developed \\ model to date cannot be used as there is inadequate regulation of donor insemination among United States sperm \\ banks. (Fertil Steril ${ }^{\circledR} 2009$; $\square$ : $\square$. (C)2009 by American Society for Reproductive Medicine.)
}

Internationally, there is much divergent opinion concerning how assisted reproductive technology (ART) practices should be supervised (1) and, as stated in the International Federation of Fertility Societies (IFFS) Surveillance 2007 (1), countries govern their ART practices by using either legislation (hereafter referred to as regulation) or guidelines. One technique used in ART is donor insemination (DI), which brings together four main stakeholders: ART providers, gamete donors, recipient parents and DI offspring (2). Regarding the supervision of DI, there are a number of issues that affect all or some of these stakeholders, including: the degree of donor anonymity (2-6); the degree of, and differentiation between, screening and testing of potential donors (7); the number of families to whom any one donor can provide gametes $(8$, 9 ); the effect of payment for sperm (10-15); and the eligibility criteria for donor insemination (1). This paper discusses the important distinction between regulation and guidelines in regard to ART supervision, the advantages and disadvantages of regulation, and the need for greater regulation in the United States to safeguard the rights and welfare of the DI child. The author maintains that the establishing of a mandatory federal donor registry, as recommended by Cahn (16), would benefit the welfare of the DI child by enabling the implementation of an updated model to assist policy makers in setting sperm donor limits to reduce the risk of half-sibling mating resulting from the multiple use of sperm donors in DI treatment $(8,17)$. A federally mandated donor registry would allow agencies to [1] centrally record the location and number of DI children each donor fathers, [2] keep track of sperm donor identity and thus help prevent multiple donations across clinics, and [3] monitor donor medical history.

\section{REGULATION VERSUS GUIDELINES}

One important distinction between mandated regulation and voluntary guidelines regarding the supervision of ART is

Received May 12, 2008; revised October 22, 2008; accepted January 12, 2009.

N.S. has nothing to disclose.

Reprint requests: Neroli Sawyer, B.Sc. (Hons), School of Behavioural and Social Sciences and Humanities, University of Ballarat, University Drive, Mount Helen, Ballarat, Victoria, 3353, Australia (E-mail: n.sawyer@ ballarat.edu.au). that it is difficult to document to what degree guidelines are followed $(1,4,16,18)$. This distinction is the primary advantage of regulation over guidelines in this context. Anecdotal evidence suggests that, in the United States, where governing is by guidelines, violation of some aspects may be widespread (1). The IFFS Surveillance 2007 report (1) indicated that there is evidence that guidelines regarding the number of embryos to be transferred are not being heeded. This was evident, at the time, by the ongoing high rate of multiple births. It is well documented that there are serious consequences, for both mother and child, associated with multiple births $(19,20)$. If this guideline-which addresses a practice with such serious consequences-was being violated, then what other guidelines-which have less immediate or obvious ramifications-are not being heeded? Specifically regarding DI, there has been concern raised about the observance of guidelines relating to donor screening for DI $(4,20-23)$. Further, there is anecdotal evidence suggesting that guidelines, regarding donor limits $(24,25)$ and the keeping of records that would enable families to access donor information for medical purposes, are not being followed (4, $16,21-27)$. In addition, there is evidence to suggest that even mandated U.S. Food and Drug Administration (FDA) regulations are not necessarily followed by at least some agencies or clinics. This was evident when the Centers for Disease Control and Prevention (CDC) contracted out the collection of data on ART procedures performed in 2004 (19), and it was discovered that $11 \%$ of ART medical centers did not report their 2004 data, despite the federal mandate (28). This raises the question that, if mandated FDA regulations are not always being followed, how likely is it then that voluntary guidelines are also not being heeded?

Currently in the Unites States, there are actually few federal regulations that require the DI industry to consider the best interests and rights of the children they help to create $(2,4,15,16,29)$. The FDA oversees the laws regarding the safety of gamete handling and the minimum requirements for screening and testing of donors (7); however, although it mandates the reporting of ART success rates $(16,19,30)$ it does not require records be kept regarding DI or the reporting of DI success rates $(16,31,32)$. This is one reason why there is a call for the establishing of a mandatory national 
registry of donor gametes $(4,16,33)$. A federal registry would record the identity of all donors and DI success rates and thus assist authorities in monitoring and tracking gamete donation across the country. This would detect, among other things, whether a donor was providing gametes to numerous banks and potentially numerous families across multiple jurisdictions.

There are disadvantages, however, to regulating ART practices. For example, ART regulation that specifically relates to restrictions on eligibility criteria, such as in countries that do not make ART available to single women or lesbian couples, can lead to reproductive tourism $(1,34-36)$. In addition, regulation regarding the revocation of donor anonymity in DI ( 2 , $4,36-38)$ can lead to a reduction in available donors $(1,4,12$, $16,39)$. In countries where both or either of these regulations are in place, they are designed, in part, to safeguard the rights and welfare of the DI child (4, 40-42). These regulations can, on the other hand, potentially disadvantage the clinics and gamete providers $(4,39)$, and possibly the potential parents, if they are not eligible for DI treatment or have to wait for a donor to become available $(11,16,43)$. The eligibility issue is not relevant to the Unites States, however, and approximately $50 \%$ of DI customers are currently single women or lesbian couples (4).

Considering the advantages and disadvantages of regulation, the author suggests that adequate regulation of DI could perhaps be defined as regulation that first safeguards the interests and rights of the DI child in regard to their physical, mental, and emotional well being, accounting for any risk to the child, including that of inherited disorders and psychological damage $(1,40,44,45)$; second, it considers the rights and welfare of the recipient parents and gamete donors (46). There are many who are of the opinion that the rights and best interest of the DI child should be the most important consideration in the ART process, and that the rights of no other stake holder should have precedent over that of the resultant child $(4,40,44,47-51)$. This view is in keeping with the United Nations Convention on the Rights of the Child (52).

The success of regulation in other countries can perhaps only be assessed by first considering what constitutes success. If the rights and welfare of all stakeholders have been considered under the regulation, and the welfare of the DI child has been the primary consideration, then perhaps success could be said to have been achieved (16). This can possibly be gauged by which of the four primary stakeholdersART providers, gamete donors, recipient parents, or adult offspring - are voicing the most dissent. If the dissension is primarily from the ART providers, as in the United Kingdom (47) and other countries where anonymity has been revoked $(1,53)$, then perhaps some success has been achieved. If dissension, however, is from those advocating the rights and welfare of DI children $(4,21,33,40,44,45,49,51)$ and anecdotally, from DI children and their parents $(24,25,54$ 56) - as is currently the case in the United States-perhaps further investigation, as is recommended in this paper, should be undertaken to establish what processes can be imple- mented to more fully meet the interests of the increasing number of DI offspring and their families. There are many advocates, in the United States and elsewhere, either requesting or advising for more regulation of DI because they believe that the current system is inadequate and not properly protecting the rights and welfare of DI offspring $(2,4,16,21$, 57-59).

\section{ANONYMITY}

As previously mentioned, the revocation of anonymity in Europe and the United Kingdom has resulted in a considerable decrease in the number of donors (1), and U.S. sperm banks insist that it would devastate the U.S. industry to have mandatory identity disclosure (32). Thus, sperm banks routinely turn down offspring asking for donor identities (25), although pressure from single women and lesbian couples has led some banks in the United States to establish "identification consent" donor programs (54) and "open donor" lists that offer more money to men willing to be identified. Donor anonymity is a controversial issue $(4,16,32)$, and the revocation of donor anonymity has resulted in reduced availability of gamete donors in some countries $(1,4,10$, $12,16,39$ ), many still think that availability of donors is not as important as the rights of the DI child to have access to information about their genetic heritage $(4,16,40,44$, $50,51)$. Although it is true that there is a natural social problem relating to unknown paternity, Sylvester suggests that it is unethical to create a situation that results in unknown paternity by deliberately creating children who can never know their biological origins (4). Currently in the United States, there are no reliable records kept regarding the number of DI children (16) or the number of children who do not know the identity of their biological father (60). Thus, there are no statistics available to compare the number of DI children who don't know the identity of their biological father to other children with unknown paternity.

\section{GENETIC HERITAGE}

There is anecdotal evidence suggesting that DI children are actually more interested in their genetic heritage than in identifying and having an on-going relationship with their donor father (54). In recent years, the World Wide Web has made it possible for DI offspring to trace information about their donor father and DI half-siblings through the matching of donor identification numbers (24). Although these DI offspring are not necessarily making contact with their donor fathers, halfsiblings are establishing contact with each other, and a new form of extended biological family is evolving $(25,56)$. Having knowledge of the genetic heritage or genotype that an individual inherits from their parents $(33,49,58,61-67)$ is an important concern for many DI children $(29,49)$. Genetic heritage determines an individual's hereditary potentials and limitations (66), and it is well documented that although the environment strongly influences the physical, mental, and emotional development of an individual $(68,69)$, so do the genes inherited from both mother and father (61). Illnesses 
are also strongly affected by genetic makeup, as well as how emotional stress, anger, or depression is experienced $(61,70)$. Significantly, medical genetics has become an integral part of preventive medicine (67). Knowledge of genetic makeup allows humans to understand why they are the way they are, helps provide a sense of identity, and allows people to comprehend their potential strengths and limitations (4, 29, 40, $41,49)$. The importance of knowing one's genetic heritage or makeup is asserted by the ethics committee of the American Society for Reproductive Medicine, which noted that "with respect to disclosure: clinicians, mental health professionals, academics, and children themselves have in recent years called for more openness in donor conception in order to protect the interests of offspring. Because of persons' fundamental interest in knowing their genetic heritage and the importance of their ability to make [informed health case decisions in the future] the Ethics Committee supports disclosure about the fact of donation to children. It also supports the [gathering and storage of medical and genetic information] that can be provided to offspring if they ask" (33). The establishing of a national donor register would enable the closer monitoring, reporting, and matching of all DI births and donors across the country and enable DI children to have access to information regarding their genetic heritage. This could be facilitated without the need to disclose identifying information $(4,16)$.

\section{GENETIC DISEASE}

The use of donor sperm has made it possible for relatively rare genetic diseases to affect many more families than before DI was used (16). In addition, there is evidence to suggest that there is ongoing concern from DI clients and health industry authorities concerning the spread of undetected genetic disease (16). Although the FDA requires donor agencies to screen for several communicable diseases (including HIV) and some genetic disorders, DI practitioners must gain permission from the donor to test beyond the common genetic disorders and are not obliged to inform new clients of health problems among a donor's previous children $(4,22,23)$. Agencies are permitted to [1] set their own limits on donor use, [2] rely on the donors to accurately relay information about their family medical history and important genetic information (7), and [3] provide whatever remuneration they deem appropriate. Although many providers claim that anonymity is best for all parties (25), critics maintain that the industry's preference for anonymity allows it to escape accountability and to avoid imposing limits on popular donors $(16,32)$. There is also concern regarding the fact that "donation" implies that there is no payment $(14,16,39,71)$ and that compensation could entice men to potentially falsify or withhold information and thereby exploit recipient families (14$16,72)$. This further underscores the need for centralized regulation and monitoring. At the very least, the number of DI children fathered by a given donor should be recorded in a national database, which would then enable the potential spread of genetic disease to be monitored. A national donor registry would also assist in the calculation of variable values for use in an up-to-date model that predicts the possible number of halfsibling matings resulting from the multiple use of sperm donors in a given location. This information could then assist policy makers in setting limits on donor use to reduce the risk of half-sibling mating and the associated possibility of genetic abnormalities in their offspring $(8,17,73,74)$.

\section{HALF-SIBLING MATING}

The potential number of half-sibling matings resulting from the multiple use of sperm donors has been difficult to estimate, because exact numbers of offspring born as a result of DI are unknown (32). In 1980, Curie-Cohen developed a model to predict the number of half-sibling matings likely to occur, per year, as a result of multiple use of sperm donors in the United States (8). The model required values for the number of sperm donors used in a given location, the average number of possible half-sibling matings per donor and the probability that a pair of half-siblings will mate. This knowledge was then intended for use in the setting of an optimal or maximum number of children per sperm donor for any state, or designated region, within the United States (8). Because the data used for the model were drawn from the late 1950s through to the late 1970s, the demographic variable values have changed (75-80), as have the cohort seeking and accessing DI treatment $(26,81-83)$ and donor profiles $(2,13,47)$. Therefore, the author's recent attempt to predict the number of half-sibling mating for the present day in the United States has been frustrated because of difficulties in implementing Curie-Cohen's 1980 model. The accuracy of the model has been weakened by [1] changes in the DI industry and [2] changes in population demographics.

Firstly, and most significantly, the commercialization of sperm banks has contributed to the inadequate monitoring and reporting of DI births $(4,16,21,57,58)$ with subsequent difficulties in tracking both the geographic location and the number of DI children per donor $(25,32)$. In 1989 there were approximately 135 banks across the United States, but as a result of commercialization and the soaring costs associated with donor recruitment and screening, in 2001 there were only 28 banks left-in just 16 states (32). Seven of those were in California, three in New York, three in Minnesota, and 15 were scattered across other states with approximately half $(46 \%)$ of all donor sperm coming from the five biggest banks. It is reported that there are currently 25 sperm banks across the United States that have, in total, approximately 1,630 registered donors (31). Therefore, a woman, with assistance from her physician, can now choose and order donor sperm on-line from a large sperm bank and have it shipped across the country $(32,84)$. This has significant ramifications for the calculation of variable values in Curie-Cohen's model.

Secondly, the establishing of large centralized sperm banks has led to the probability of a DI child being born in the same state as a half-sibling to become much less likely. In addition, 
the number of donors per state-a crucial variable in CurieCohen's model-is impossible to determine because of sperm being shipped across state borders. A donor's DI children are now less likely to be born or married in the same state as his natural children or as each other. There is evidence to suggest that the degree of national migration has changed, with the level of migration of donors and recipient families $(76,77,80,85)$ having dropped since the early 1980 s and is ultimately, as with the DI children themselves, continuing to do so $(80,86-91)$. In addition, because of an increase in the number of children being born outside of formal marriage arrangements $(31,32,92)$ the use of marriage data for determining variable values is no longer valid and the calculation of the proportion of marriages between people born in the same state is no longer relevant. Accordingly, a different means for estimating assortive mating for geography will need to be developed and will undoubtedly alter the calculated number of possible half-sibling matings resulting from DI. A new, updated model can only be developed and be of use when there is adequate reporting and recording of vital statistics, such as the number and location of DI births $(4,16,21)$ and number of DI children per donor. This recording would be facilitated by a nationally mandated donor registry.

A centralized registry would also enable the calculation of the average number of possible half-sibling matings per donor-another crucial variable in Curie-Cohen's modeland the average number of DI children per donor (93) could then be computed. It is reported that, in 1990, there were 20,000 DI births in the United States (81). In addition, there are reports that the number of donor-conceived offspring is increasing, with numbers still estimated to be between $30,000-60,000(16,26,82)$. Informal guidelines from the American Society for Reproductive Medicine on donor limits currently recommend no more than 20 births per donor for a region of 800,000 people (7). However, one bank apparently allows up to 52 children per donor, and the national average is thought to be between 20 and 30 (22). As already mentioned, there is a federal mandate to record success rates for ART by recording all live births per ovarian stimulation procedure (19). There are, however, no records kept that track DI success rates, and adherence to guidelines for limiting offspring is voluntary $(16,31,32)$. In addition, as women are not required to report DI births it is quite likely that many donors could have over 30 children. Therefore, in the absence of any centralized records $(4,16,21,27)$, the number of children born each year as a result of DI and the identity their donors, cannot be reliably established (16).

Therefore, the need to establish a federal donor registry to monitor the numbers and location of donors and their DI offspring is fundamentally linked to regulation that will protect the rights and welfare of the DI child is. This registry will enable the development of an updated model to determine the probability of half-sibling mating and protect DI children from accidentally forming incestuous relationships $(4,16$, 17).

\section{DISCUSSION AND RECOMMENDATIONS}

Currently in the Unites States there are voluntary guidelines, but no regulations that set limits to the use of donor sperm (16). The DI industry appears to operate as a commercial, for-profit industry that is primarily focused on treating adult infertility and does not view the rights and welfare of the DI offspring as the most important consideration in the DI process (4). It is true that there are many clinicians who are concerned about the welfare of all their clients (46), but generally in the United States, the DI industry appears to put the rights of the donor to remain anonymous and the desires of infertile couples above the rights and welfare of the DI offspring (4, $16,20,21,32,57)$. Certainly, changes in recommendations regarding management of DI continue to be made, but whether changes in recommendations are likely to be heeded and what agency monitors this is open to question $(1,19)$.

There is a call for the mandatory reporting and recording of all donors and their DI offspring in a centralized register. This call comes from those who are concerned with the rights and welfare of DI children $(4,16,21,94)$ as well as from the popular media. Anecdotal evidence through the media primarily comes from advocacy groups (24) and individuals concerned with having access to information about their genetic heritage and knowledge about potential half-siblings (22, 24, 25, 31, $54,55)$.

It is acknowledged that the establishing of a national donor registry would be complex given the Health Insurance Portability and Accountability Act (HIPAA) in the United States (95) and that a donor registry could not be enforced retrospectively. Consequently, it would apply to future donors-possibly recruited by different means $(10,11,15,43)$ and donating for different reason $(13,47,96)$ - and future recipient parents and offspring who would be encouraged to increasingly regard openness about genetic origins to be the norm $(3,40$, $44,48-50,62,97-101)$, as is currently the case with adoption (16).

The author recommends that a nationally mandated registry of donors and donor offspring be established. The purpose of this registry is fourfold: [1] that donors will be prevented for making multiple, untracked donations in different locations (16), [2] that comprehensive health and genetic information can be available before sperm is offered for sale (23), [3] that women can be informed as to how many children a donor has, and in what location (31); and [4] that an industry ethics code guarantees that DI children will have access to knowledge about their genetic heritage (25). In addition, the author recommends that the increasingly urgent and significant legal and ethical challenges $(4,16,102)$ regarding sperm donor anonymity, disclosure and the setting of sperm donor limits continue to be investigated. There is an increasing awareness that genetic information is important to the establishment of identity for the DI child and in preventative medicine $(4,67)$, as well as an increasing ability for DI children to independently discover the identity of their donor through genetic data bases and the Internet. There is also 
an increasing body of opinion that recommends that disclosure of DI origins serve the best interest of the DI child $(33,40,44,48,62)$, and there is the need to provide policy makers with criteria for setting sperm donor limits, to monitor the possible number of half-sibling matings that could result from the multiple use of sperm donors $(8,17,103,104)$.

\section{CONCLUSION}

The establishing of a mandatory donor gamete registry would assist in the creation of an updated model for predicting the number of half-sibling matings that could result from the multiple use of donors in DI. Currently, there are difficulties in calculating the values for variables used in Curie-Cohen's model. However, improved reporting and recording of donor identities and DI births in a national registry would generate data that [1] would reflect changing reproductive trends and social conditions and [2] can be used in an updated model for use as a tool by policy makers to establish donor limits in any given location (17).

Regulation does not solve all problems, and to require regulation only to facilitate the updating of Curie-Cohen's model would not be justified. Minimizing the risk of half-sibling mating is valuable, but is only one of the reasons why a national donor registry is important (16). There is an equally important consideration: the right of the DI offspring to have access to information about their genetic heritage and the medical history of their donor $(33,48-50,57,58,62$ $64,105,106)$. Mandatory reporting of the number DI births, how many children an individual donor has fathered, and the identity and profile of every donor with updated medical records (18) would make possible the recording of information that could assist agencies in keeping track of children born through gamete donation and enable them to provide DI offspring with important genetic information $(4,16)$.

Acknowledgements: I would like to acknowledge the valuable feedback from my supervisor, Associate Professor John McDonald.

\section{REFERENCES}

1. Jones H, Cohen J, Cooke I, Kempers R. IFFS surveillance 2007. Fertil Steril 2007;87(Suppl 1):S1-67.

2. Daniels K. Donor gametes: anonymous or identified? Clin Obstet Gynaecol 2007;21:113-28.

3. Daniels K, Meadows L. Sharing information with adults conceived as a result of donor insemination. Hum Fertil 2006;9:93-9.

4. Sylvester T. The case against sperm donor anonymity. New Haven, CT: Yale Law School, 2007.

5. Lycett E, Daniels K, Golombok S. School-aged children of donor insemination: a study of parents' disclosure patterns. Human Reproduction 2005;20:810-9.

6. Brewaeys A, Bruyn JK, Louwe 1A, Helmerhorst FM. Anonymous or identity-registered sperm donors? A study of Dutch recipients' choices. Hum Reprod 2005;20:820-4.

7. Practice Committee of the American Society for Reproductive Medicine; Practice Committee of the Society for Assisted Reproductive Technology. 2006 Guidelines for gamete and embryo donation. Fertility and Sterility 2006;86(Suppl 5):S38-50.
8. Curie-Cohen M. The frequency of consanguineous matings due to multiple use of donors in artificial Insemination. Am J Hum Genet 1980;32:589-600.

9. Wang C, Tsai M, Lee M, Huang S, Kao C, Ho H, et al. Maximum number of live births per donor in artificial insemination. Hum Reprod 2007;22:1363-72.

10. Daniels K. Recruiting gamete donors: response to Craft and Thornhill. Reprod Biomed Online 2005;10:430-1.

11. Craft I, Thornhill A. Would 'all-inclusive' compensation attract more gamete donors to balance their loss of anonymity? Reprod Biomed Online 2005;10:301-6.

12. Craft I. Will removal of anonymity influence the recruitment of egg donors? A survey of past donors and recipients. Reprod Biomed Online 2005;10:325-9.

13. Shenfield F. Too late for change, too early to judge, but an oxymoron will not solve the problem. Reprod Biomed Online 2005;10: 433-5.

14. Shenfield F, Steele SJ. A gift is a gift, or why gamete donors should not be paid. Hum Reprod 1995;10:253-5.

15. Daniels K. To give or sell human gametes-the interplay between pragmatics, policy and ethics. J Med Ethics 2000;26:206-11.

16. Cahn N. Necessary subjects: the need for a mandatory national donor gamete registry. DePaul J Health Care Law 2008.

17. Sawyer N, McDonald J. A review of mathematical models used to determine sperm donor limits for fertility treatment. Fertil Steril 2008;90: 265-71.

18. Practice Committee of the American Society for Reproductive Medicine; Society for Assisted Reproductive Technology. Revised minimum standards for practices offering assisted reproductive technologies. Fertil Steril 2003;80:1556-9.

19. Wright VC, Chang J, Jeng G, Chen M, Macaluso M. Assisted reproductive technology surveillance - United States, 2004. MMWR Surveill Summ 2007;56:1-22.

20. Andrews L. The clone age: adventures in the new world of reproductive technology. New York: Henry Holt and Company, 1999.

21. Ginsberg K. FDA approval? A critique of the artificial insemination industry in the United States. Univ Mich J Law Reform 1997;30: 825-51.

22. Audi T. Birmingham case raises question: do banks find out enough about donors? Detroit Free Press, 2006; May 22.

23. Wolff J. The truth about donor 1084. Self 2006. Available at http:// www.self.com. Last accessed 22 September, 2007.

24. Kramer W. Redefining family. The Donor Sibling Registry 2000. Available at http://www.donorsiblingregistry.com. Last accessed 22 September, 2007.

25. Harmon A. Are you my sperm donor? Few clinics will say. New York Times 2006; January 20.

26. U.S. Congress Office of Technology Assessment. Artificial insemination: practice in the United States: summary of a 1987 survey-background paper, OTA-13P-BA-48. Washington, DC: U.S. Government Printing Office, 1988.

27. Elster N. All or nothing? The international debate over disclosure to donor offspring. Biotechnology and the Human Future 2006. http:// www.thehumanfuture.org/commentaries/assistedreproductivetechnology/ art_commentary_elsterol.html. Last accessed 17 July, 2007.

28. Centers for Disease Control and Prevention, American Society for Reproductive Medicine, Society for Assisted Reproductive Technology. 2004 assisted reproductive technology success rates. Atlanta, GA: U.S. Department of Health and Human Services, Centers for Disease Control and Prevention, 2006.

29. Basu S. Genetic privacy: resolving the conflict between the donor and the child. Curr Sci 2004;86:1363-5.

30. Centers for Disease Control and Prevention. 2005 assisted reproductive technology success rates: national summary and fertility clinic success rates. Atlanta, GA: U.S. Department of Health and Human Services, Centers for Disease Control and Prevention, 2007.

31. DiLascia P. How many children? SpermCenter 2006. Available at www.spermcenter.com. Accessed September 2007. 
32. Daniels C, Golden J. Procreative compounds: popular eugenics, artificial insemination and the rise of the American sperm banking industry. (Industry overview). J Soc History 2004;38.

33. Ethics Committee of the American Society for Reproductive Medicine. Informing offspring of their conception by gamete donation. Fertil Steril 2004;81:527-31.

34. Matorras R. Reproductive exile versus reproductive tourism. Hum Reprod 2005;20:3571.

35. Spar D. Reproductive tourism and the regulatory map. N Engl J Med 2005;325:531-3.

36. Sauer MV. Further restrictions on egg donation in the UK: two strikes and you're out! Reprod Biomed Online 2005;10:431-3.

37. Grace V, Daniels K, Gillett W. The donor, the father, and the imaginary constitution of the family: Parent's constructions in the case of donor insemination. Soc Sci Med 2008;66:301-14.

38. van den Akker O. A review of family donor constructs: current research and future directions. Hum Reprod Update 2006;12:91-101.

39. Daniels K, Feyles V, Nisker J, Perez-y-Perez M, Newton C, Parker J, et al. Sperm donation: implications of Canada's Assisted Human Reproduction Act 2004 for recipients, donors, health professionals, and institutions. J Obstet Gynaecol Can 2006;28:608-15.

40. Tobin J. The Convention on the Rights of the Child: the rights and best interests of children conceived through assisted reproduction. Melbourne, Australia: Victorian Law Reform Commission, 2004.

41. Shenfield F, Steele SJ. What are the effects of anonymity and secrecy on the welfare of the child in gamete donation. Hum Reprod 1997;12: $392-5$.

42. Shenfield F. Privacy versus disclosure in gamete donation: a clash of interest, of duties, or an exercise in responsibility? J Assist Reprod Genet 1997;14:371-3.

43. Pennings G. Commentary on Craft and Thornhill: new ethical strategies to recruit gamete donors. Reprod Biomed Online 2005;10:307-9.

44. Nicholson A. Children's rights in the context of infertility treatment. In: Symposium ITAOD, editor. What About Me? The best interests of the child; 2006; Treetops Room, Museum of Victoria, Carlton Gardens, Nicholson Street, Carlton, Melbourne; 2006.

45. Hodgkin R, Newell P. Implementation handbook for the convention on the rights of the child: fully revised third edition. UNICEF, Geneva, 2007.

46. Stern J, Cramer C, Green R, Garrot A, DeVries K. Determining access to assisted reproduction technology: reactions of clinic directors to ethically complex case scenarios. Hum Reprod 2003;18:1343-52.

47. Blyth E, Frith L. The UK's gamete 'crisis' - a critical analysis. Critical Social Policy 2008;28:74-95.

48. Blyth E. Donor assisted conception and donor offspring rights to genetic origins information. Int J Children's Rights 1998;6:237-53.

49. McWhinnie A. Debate on gamete donation and anonymity: should offspring from donated gametes continue to be denied knowledge of their origins and antecedents? Hum Reprod 2001;16:807-17.

50. McGee G, Brakman S, Gurmankin AD. Debate-continued: Gamete donation and anonymity-disclosure to children conceived with donor gametes should not be optional. Hum Reprod 2001;16: 2033-8.

51. Daniels KR. Artificial insemination using donor semen and the issue of secrecy: the views of donors and recipient couples. Soc Sci Med 1988;27:377-83.

52. UNICEF. Convention on the Rights of the Child. 2002. http://www.unicef.org/acc/index_30177.html. Last accessed 8 July, 2008.

53. Johnson M. Escaping the tyranny of the embryo? A new approach to ART regulation based on UK and Australian experiences. Hum Reprod 2006;21:2756-65.

54. Streisand B. Who's your daddy?: U.S. News and World Report 2006; May 2.

55. Allen-Milles T. Hi there, I'm your sperm donor sis. The Sunday Times 2006; March 5.

56. CBS News. Sperm donor siblings find family ties. In: United States. CBS Broadcasting, 2007.
57. Shanley M. Collaboration and commodification in assisted procreation: reflections on an open market and anonymous donations in human sperm and eggs. Law Soc Rev 2002;36:257-84.

58. Baines J. Gamete donors and mistaken identities: the importance of genetic awareness and proposals favoring donor identity disclosure for children born from gamete donations in the United States. Family Court Review 2007;45:116-32.

59. Frith L. Gamete donation and anonymity: the ethical and legal debate. Hum Fertil 2001;16:818-24.

60. Anderson K. How well does peternity confidence match actual paternity? Evidence from worldwide nonpaternity rates. Curr Anthropol 2006;43:511-8.

61. Breastcancer.org. Your Genetic Makeup. Day-to-Day Matters; 2007.

62. Blyth E. Information on genetic origins in donor-assisted conception: is knowing who you are a human rights issue? Hum Fertil 2002;5:185-92.

63. D'Orazio P. Half of the family tree: a call for access to a full genetic history for children born by artificial insemination. Health Biomed Law 2006;2.

64. Sants H. Genealogical bewilderment in children with substitute parents. Br J Med Psych 1964;37:133-41.

65. Blamire J. Definition: genotype. In: Science at a distance. New York: Brooklyn College, 2000.

66. Encyclopaedia Britannica. Definition: genotype. In: Biology: Encyclopædia Britannica, Inc.

67. McGraw-Hill Encyclopedia of Science and Technology, 5th ed. Human Genetics. In: Sci-Tech Encyclopedia. McGraw-Hill.

68. Lerner R. Nature, nurture, and dynamic interactionism. Hum Dev 1978;21:1-20.

69. Rutter M. Nature-nurture integration: the example of antisocial behavior. Am Psychol 1997;52:390-8.

70. Jang K, Livesley WJ, Vernon PA. Heritability of the big five personality dimensions and their facets: a twin study. J Pers 2006;64:577-91.

71. Shenfield F. Gamete donation: ethical implications for donors. Hum Fertil 1999;2:98-101.

72. ESHRE Task Force on Ethics and Law. III. Gamete and embryo donation. Hum Reprod 2002;17:1407-8.

73. Seeminova E. A study of children of incestuous marriages. Hum Hered 1971;21:108-28.

74. Rogers JG, Danks DM. The genetic consequences of incest. Med J Aust 1978;2:362-3.

75. Lee S, Edmonston B. New marriages, new families: U.S. racial and hispanic intermarriage. Popul Bull 2005;60.

76. Shrestha L. The changing demographic profile of the United States: CRS Report for Congress. Congressional Research Service, 2006.

77. Hobbs F, Stoops N. Demographic trends in the 20th Century: U.S. Department of Commerce. Economic and Statistics Administration. Washington, D.C.: U.S. Census Bureau, 2002.

78. Lee M, Mather M. U.S. labor force trends. Popul Bull 2008;63.

79. Martin P, Zucher G. Managing migration: the global challenge. Popul Bull 2008;63.

80. Wellner A. Is 'increasing mobility' a threat to U.S. elder care? In: Population Reference Bureau, 2005.

81. Han J, Brannigan R. Donor insemination and infertility: what general urologists need to know. Nat Clin Pract Urol 2008;5:151-8.

82. Shapiro S, Saphire D, Stone W. Changes in American A.I.D. practice during the past decade. Int J Fertil 1990;35:284-91.

83. Ferrara I, Balet R, Grudzinskas J. Intrauterine donor insemination in single women and lesbian couple: a comparative study of pregnancy rates. Hum Reprod 2000;15:621-5.

84. Pennings G. The right to choose your donor: a step towards commercialization or a step towards empowering the patient? Hum Fertil 2000;15:508-14.

85. National Center for Health Statistics. Vital Statistics of the United States, 1988. Volume 111, Marriage and Divorce; 1996.

86. Wolf D, Longino C. Our "increasingly mobile society"? The curious persistence of a false belief. Gerontologist 2005;45:5-11. 
87. Schachter J. Geographic Mobility: 2002 to 2003. In: Current Population Reports. Washington, D.C.: U.S. Census Bureau, 2004.

88. U.S. Census Bureau. Immigration, outmigration, and net migration for metropolitan areas: 1985-2006. In: Historical data from current population survey (CPS). Washington, D.C.: U.S. Census Bureau, 2008.

89. U.S. Census Bureau. State of Residence in 2000 by state of birth: 2000 (PHC-T-38). Washington, D.C.: U.S. Census Bureau, 2008

90. U.S. Census Bureau. Annual geographic mobility rates, by type of movement: 1947-2006. In: Historical data from current population survey (CPS). Washington, D.C.: U.S. Census Bureau, 2008.

91. U.S. Census Bureau. People on the move: geographic mobility, 199899. Washington, D.C.: U.S. Census Bureau, 1999.

92. U.S. Central Intelligency Agency. People in the United States. In: CIA World Fact Book. Washington, D.C.: U.S. Central Intelligence Agency, 2006.

93. Curie-Cohen M, Luttrel L, Shapiro S. Current practice of artificial insemination by donor in the United States. N Engl J Med 1979;300: 585-90.

94. Johnson M, Petersen K. Public interest or public meddling? Towards an objective framework for the regulation of assisted reproduction technologies. Hum Reprod 2008;23:716-28.

95. Wilson J. Health Insurance Portability and Accountability Act Privacy Rule causes ongoing concerns among clinicians and researchers. Ann Int Med 2006;145:313-6.
96. Blyth E, Frith L, Farrand A. Is it possible to recruit gamete donors who are both altruistic and identifiable? Fertil Steril 2005;84(Supp 1):S21.

97. Anderson L. Fertility treatment no longer an issue to hide: don't hold back in telling children. The Adelaide Advertiser 2004; October 15.

98. Infertility Treatment Authority. It's time to tell children about donor conception. http://www.ita.org. Last accessed 4 April, 2007.

99. Rumball A, Adair V. Telling the story: parents' script for donor offspring. Hum Reprod 1999;14:1392-9.

100. Murray C, MacCallum F, Golombok S. Egg donation parents and their children: follow-up at age 12 years. Fertil Steril 2006;85:610-8.

101. Nachtigall RD, Tschann JM, Quiroga SS, Pitcher L, Becker G. Stigma, disclosure, and family functioning among parents of children conceived through donor insemination. Fertil Steril 1997;68:83-9.

102. Stephen E. Assisted reproductive technologies: is the price too high? Population Today 1999;27:1-2.

103. Egeland T. Excessive use of a single donor? An inadvertent consanguinity. Fertil Steril 1997;67:1181-2.

104. McDonough PG. Excessive use of a single donor? An inadvertent consanguinity. Fertility and Sterility 1997;67:1183-5.

105. Shenfield F. To know or not to know the identity of gametes donors? The UK and European legal context. J Assist Reprod Genet 2004;21: 95-6.

106. Frith L. Gamete donation, identity, and the offspring's right to know. Virtual Mentor: American Medical Association Journal of Ethics 2007;9:644-8. 